\title{
High-Stress Compressive Creep Behavior of Ti-6Al-4V ELI Alloys with Different Microstructures
}

\author{
Zhenhua Dan ${ }^{1,2,3,4 *}$, Jiafei Lu ${ }^{1,2}$, Hui Chang ${ }^{1,3,4}$, Ping Qu ${ }^{5}$, Aifeng Zhang ${ }^{5}$, Zhigang Fang ${ }^{6}$, Yuecheng Dong ${ }^{1}$, \\ Ying Wang ${ }^{2}$, Lian Zhou ${ }^{1}$
}

${ }^{1}$ College of Materials Science and Engineering and Tech Institute for Advanced Materials, Nanjing Tech University, Nanjing 210009, China

${ }^{2}$ State Key Laboratory of Metal Materials for Marine Equipment and Applications, Anshan Iron and Steel Company, Anshan, 114021, China

${ }^{3}$ Jiangsu Collaborative Innovation Center for Advanced Inorganic Function Composite, Nanjing Tech University, Nanjing 210009, China

${ }^{4}$ Synergetic Innovation Center for Advanced Materials, Nanjing Tech University, Nanjing 210009, China

${ }^{5}$ China Ship Scientific Research Center, Wuxi 214082, China

${ }^{6}$ Naval Academy of Armament, Beijing 100161, China

\begin{abstract}
Influence of initial microstructure of Ti-6Al-4V ELI alloys on their compressive creep behavior at ambient temperature was investigated with applying compression stresses from 695 to $1092 \mathrm{MPa}$. The experimental results show that the basketweave alloys have better compressive creep resistances than those duplex ones. The constitutive equations in steady-state compressive creeps of duplex or basketweave structure are calculated to be $=2.77 \times 10-15(\sigma-710) 2.1$ and $=2.36 \times 10-14(\sigma-740) 1.7$ by fitting the linear regression creep curves after uniaxial compression tests. The noticeable compressive creep strains occur when the applied compression stresses are higher than the threshold stresses, i.e. $710 \mathrm{MPa}$ for duplex Ti-6Al-4V ELI alloys and $740 \mathrm{MPa}$ for basketweave alloys. Microstructural analysis indicates that the creep deformation of Ti-6Al-4V ELI alloys at ambient temperature is mainly controlled by dislocation slip. The creep behavior of Ti-6Al-4V ELI alloy with duplex microstructure is controlled by dislocation slip, like slip dislocations with a-type Burgers vector sliding on the basal or prismatic planes and a few $\mathrm{c}+\mathrm{a}$ type dislocation sliding on the pyramidal planes. While creep mechanism for basketweave ones is dislocation glide controlled by $\mathrm{c}+\mathrm{a}$ type Burgers vector sliding on the pyramidal planes and atype sliding on the basal or prismatic planes.
\end{abstract}

Keywords: Ti-6Al-4V ELI alloy, High-stress compressive creep, Constitutive equation, Dislocations.

\section{Introduction}

Titanium alloys have been widely applied in aerospace and ocean engineering due to their superior properties such as high specific strength, elastic modulus and corrosion resistance [1-3]. Ti-6Al-4V alloys has been the workhorse of the titanium industry due to their high specific strength, corrosion resistance, excellent high temperature properties and metallurgical stability[4]. It is well known that high-temperature creep performance is one of the main criteria for service spans of the titanium alloys due to the requirements of the safety and reliability of aeroengineers. The creep deformation of titanium alloys at elevated temperature has been drawing worldwide attention for many years [5-11]. At 500 and $600{ }^{\circ} \mathrm{C}$, the creep of Ti-6Al-4V appears three stages of creep and the primary creep as well as steady-state creep was controlled by dislocation climb[7]. At 375 and $470^{\circ} \mathrm{C}$, the creep deformation of Ti-5Al-2Sn-4Zr-4Mo-2Cr-1Fe alloys is controlled by dislocation creep mechanism within primary $\alpha$ phase and interface sliding within secondary $\alpha$ phases[12]. The creep mechanism discussed in literatures for titanium alloys at elevated temperature includes dislocation slip and climb [13, 14], grain boundary or interface 
sliding [12] and vacancy diffusion[6]. Less attention has been paid to creep deformation at ambient temperature (T $<0.2 \mathrm{Tm}$ ) due to the fact that the creep deformation is small and unlikely to failure, especially when applied stresses are set below the yield stresses. However, several titanium alloys have been showed appreciable creeps at ambient temperature even when stress is below the yield strength of the materials[15-17]. At ambient temperature, creep curves exhibit creep saturation [15, 18], and primary creep is the dominant deformation during creep of titanium alloys[19, 20]. However, the mechanism of ambient temperature creep of titanium alloys has not been established. Several researches $[21,22]$ reported that ambient temperature creep is controlled by dislocation slip.

The high temperature creep behaviors of some typical titanium alloys, such as $\mathrm{Ti}-6 \mathrm{Al}-4 \mathrm{~V}, \mathrm{Ti}-6 \mathrm{Al}-2 \mathrm{Sn}-4 \mathrm{Zr}-2 \mathrm{Mo}$, Ti-6Al-2Sn-4Zr-2Mo-0.1Si, Ti-6.5Al-1.5Zr-3.5Mo-0.3Si[4, 9, 10], have been extensively investigated. Previous studies have shown that microstructure is an important variable affecting creep strains[18, 23-25]. For several typical microstructures of titanium alloys, some previous studies shows that basketweave and lamellar structures are more creep resistances than duplex and equiaxed structures[24, 25]. At present, the creep researches on titanium alloys are mainly concentrated on the cases under the interactions of the tensile stresses, while the creep study of titanium alloys under the interactions of the compressive stresses is relatively rare. Studies have shown that dramatic tension-compression asymmetry can be found in the creep responses of Ti-6Al-2Sn- $4 \mathrm{Zr}-2 \mathrm{Mo}$ alloys[26]. Titanium alloys are widely used in deep sea equipments, such as submarines and deep sea scientific observers. When these equipments stay in the deep sea for long time, compressive creeps due to the large hydrostatic pressure of the above seawater can cause the safety issues in the constructions. Therefore, it is necessary to put more attentions to the compressive creeps of titanium alloy. In addition, the creep mechanism of titanium alloy under compressive stress state at ambient temperature should be clarified.

In present work, the effects of creep stresses and initial microstructure of Ti-6Al-4V ELI alloys on the compressive creep behavior at ambient temperature were investigated. The creep deformation has been discussed from several aspects: movements and changes of dislocations, of Ti-6Al-4V ELI alloys tested at both high and low applied stress levels were observation by TEM. It is intended to discuss creep mechanism of Ti-6Al-4V ELI alloys at ambient temperature.

\section{Materials and experiments}

The chemical composition of Ti-6Al-4V ELI alloys (BAOTI Group Ltd.) is, in terms of weight percent, 6.1Al, $4.2 \mathrm{~V}, 0.23 \mathrm{Fe}, 0.04 \mathrm{C}$, balanced $\mathrm{Ti}$. In order to obtain duplex structure and basketweave structure, the as-received alloys have been confirmed to have duplex and basketweave microstructures. Crystalline structures of the samples were confirmed by X-ray diffraction (XRD, Rigaku, Geigerflex) with a $\mathrm{CuK} \alpha$ radiation. Specimens were etched in a Kroll solution (HF $1 \mathrm{ml}, \mathrm{HNO} 32 \mathrm{ml}$ and $\mathrm{H} 2 \mathrm{O} 7 \mathrm{ml}$ ) and then observed by metallographic optical microscopy (OM, AxioObserver.A1m, Zeiss). Compression fracture tests were performed at ambient temperature under the strain rate of $0.5 \mathrm{~mm} / \mathrm{min}$. The dimensions of compression tests specimens are $\Phi 8 \times 12 \mathrm{~mm}$. High-stress compressive creep tests at ambient temperature, hereafter abbreviated as HSCCAT, were performed with using selfdeveloped high stress compression creep tester, in a uniaxial compressive stresses range from 695 to $1092 \mathrm{MPa}$. The environmental temperature was recorded to change from $10-35{ }^{\circ} \mathrm{C}$ during the HSCCAT. The dimensions of bulk Ti-6Al-3Nb-2Zr-1Mo specimens are $\Phi 20 \times 70 \mathrm{~mm}$. The change of the sample dimensions was measured by an extensometer with an accuracy of $1 \mu \mathrm{m}$ with a time interval of $180 \mathrm{~s}$. Dislocation structures of creeped Ti-6Al-4V ELI alloys with duplex and basketweave microstructure tested at both high and low applied stress levels were observed by transmission electron microscopy (TEM FEI, Tecnai G220). The specimens for TEM observations were prepared from discs sectioned normal to the stress axis of the creeped samples. The specimens were prepared by ion milling technique using a solution consisting of 60 percent methanol, 35 percent butyl alcohol and 5 percent perchloric acid, at a voltage of $20 \mathrm{~V}$ and a temperature of $-25^{\circ} \mathrm{C}$. TEM investigations were performed at $200 \mathrm{KV}$.

\section{Results}

3.1 Microstructural characterization and compression fracture behavior of Ti-6Al-4V ELI alloys 
Fig. 1 shows X-ray diffraction (XRD) patterns of Ti-6Al-4V ELI alloys. The strong peaks at about $2 \theta=35^{\circ}$, $38^{\circ}, 40^{\circ}, 53^{\circ}, 63^{\circ}, 71^{\circ}, 77^{\circ}$ and $78^{\circ}$ correspond to (100), (002), (101), (102), (110), (103), (112) and (201) planes of hcp $\alpha$ phase, respectively. The peak at about $2 \theta=39^{\circ}$ was assigned to (110) plane of bcc $\beta$ phase. The optical metallographs of Ti-6Al-4V ELI alloys with duplex and basketweave microstructures are shown in Fig. 2. A typical duplex microstructure of $\alpha$ phase and fine intragranular $\beta$ phase is clearly observed in Fig. 2a. And a phases consist of equiaxed primary $\alpha$ phases and lamellar secondary $\alpha$ phases. The average grain sizes of equiaxed and lamellar $\alpha$ phase were $12.5 \pm 3.1 \mu \mathrm{m}$ and $1.2 \pm 0.3 \mu \mathrm{m}$, respectively. The $\beta$ phases with size of $820 \pm 120 \mathrm{~nm}$ are present at $\alpha$ phase boundaries. It is a typical basketweave microstructure of titanium alloys in Fig. $2 \mathrm{~b}$. The lamellar $\alpha$ and lamellar $\beta$ phases are interlaced to form basketweave like outlines. The average widths of lamellar $\alpha$ and lamellar $\beta$ phases were $2.3 \pm 0.4 \mu \mathrm{m}$ and $740 \pm 110 \mathrm{~nm}$, respectively. The compressive stress-strain curves of Ti6Al-4V ELI alloys with duplex and basketweave structures at room temperature is shown in Fig. 3. The values of yield strength, yield strain, ultimate strength and plastic strain of duplex structure are $992 \mathrm{MPa}, 9.42 \%, 1796 \mathrm{MPa}$ and $32.72 \%$, respectively. While the values of yield strength, yield strain, ultimate strength and plastic strain of basketweave structure are $1003 \mathrm{MPa}, 8.18 \%, 1817 \mathrm{MPa}$ and $29.24 \%$, respectively. The values of yield strengths and ultimate strengths of basketweave alloys are slightly higher than those of the duplex, but the plastic strains of basketweave structure are slightly lower than those of the duplex. This fact proves that the basketweave structure has higher strengths, while the duplex has better plasticity. Upon reaching their ultimate compression strengths, the specimen fails into two fragments with the fracture surface at $45^{\circ}$ to the compression axis[27], indicating that the shear stresses mainly cause the fracture.

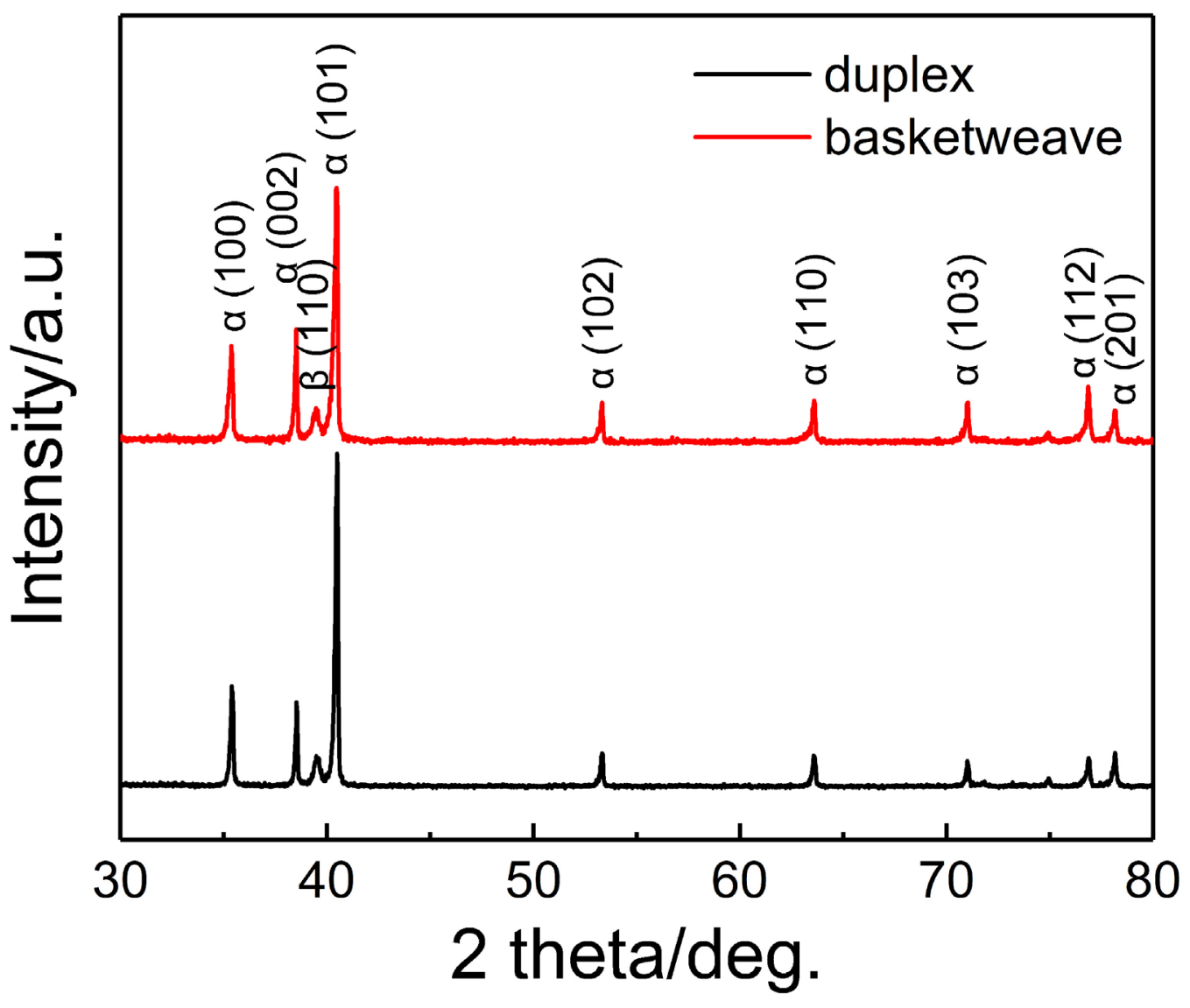

Fig. 1 XRD pattern of as-received Ti-6Al-4V ELI alloys with duplex (upper) and basketweave (lower) microstructures. 

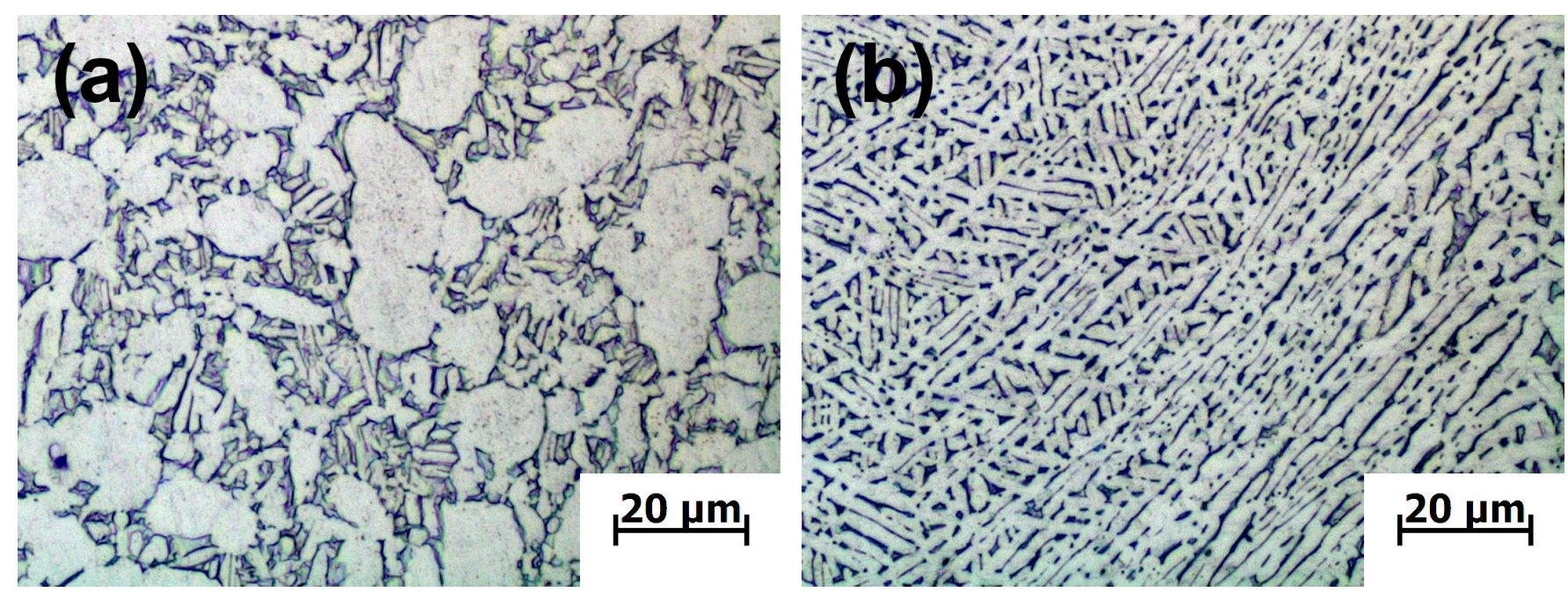

Fig. 2 Optical microscope micrographs of Ti-6Al-4V ELI alloys with duplex (a) and basketweave (b) microstructures.

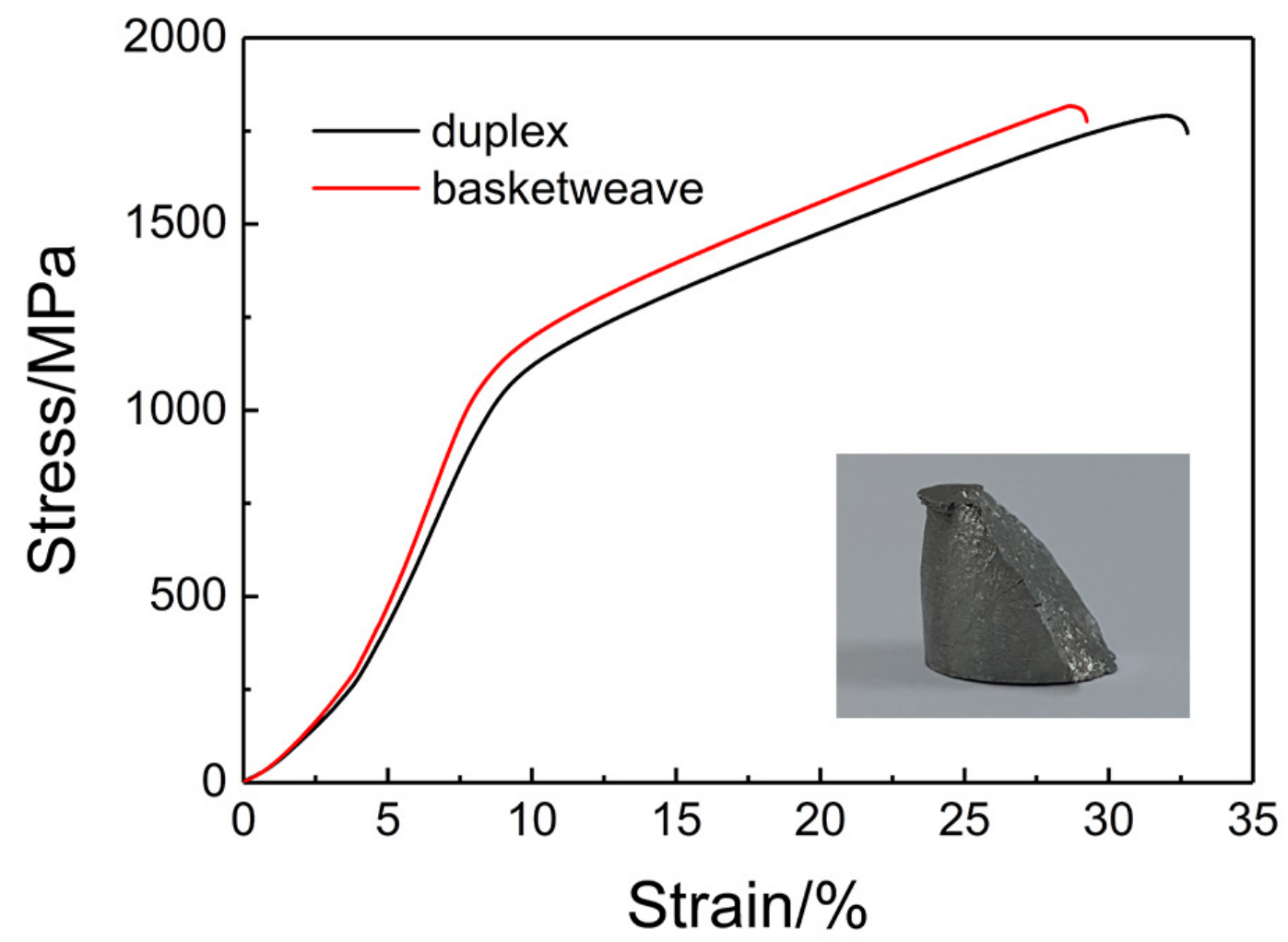

Fig. 3 Compression stress-strain curves of Ti-6Al-4V ELI alloys with basketweave (upper) and duplex (lower) microstructures.

\subsection{Compressive creep behavior of Ti-6Al-4V ELI alloys during HSCCAT}

The HSCCAT curves of the Ti-6Al-4V ELI alloy at different stress levels from 695 to $1092 \mathrm{MPa}$ are presented in Fig. 4. The creep rates are high in the beginning stages and gradually decreased to reach the steady states with increase of the creep times. These creep curves are typical and similar with others of titanium alloys at ambient temperature $[15,16,18]$. At the compressive stresses of $695 \mathrm{MPa}$, the creep rates of both duplex and basketweave alloys decreased gradually to almost zero. This phenolmenon that creep rates decrease to almost zero is so called creep saturation[18]. In this condition, creep deformations are regarded negligible. While the stresses are increased to $794,843,893$ and $1092 \mathrm{MPa}$, the second stage, so called steady-state creep stage, appears and the creep rates became almost constant. It implies the presence of the threshold compressive stresses. The creep curves exhibited creep saturation when the compressive stresses are below the threshold stresses[28]. The third accelerated creep 
stage was absent in all compressive creep curves, which might due to the limited duration time of HSCCATinduced compressive creep tests.

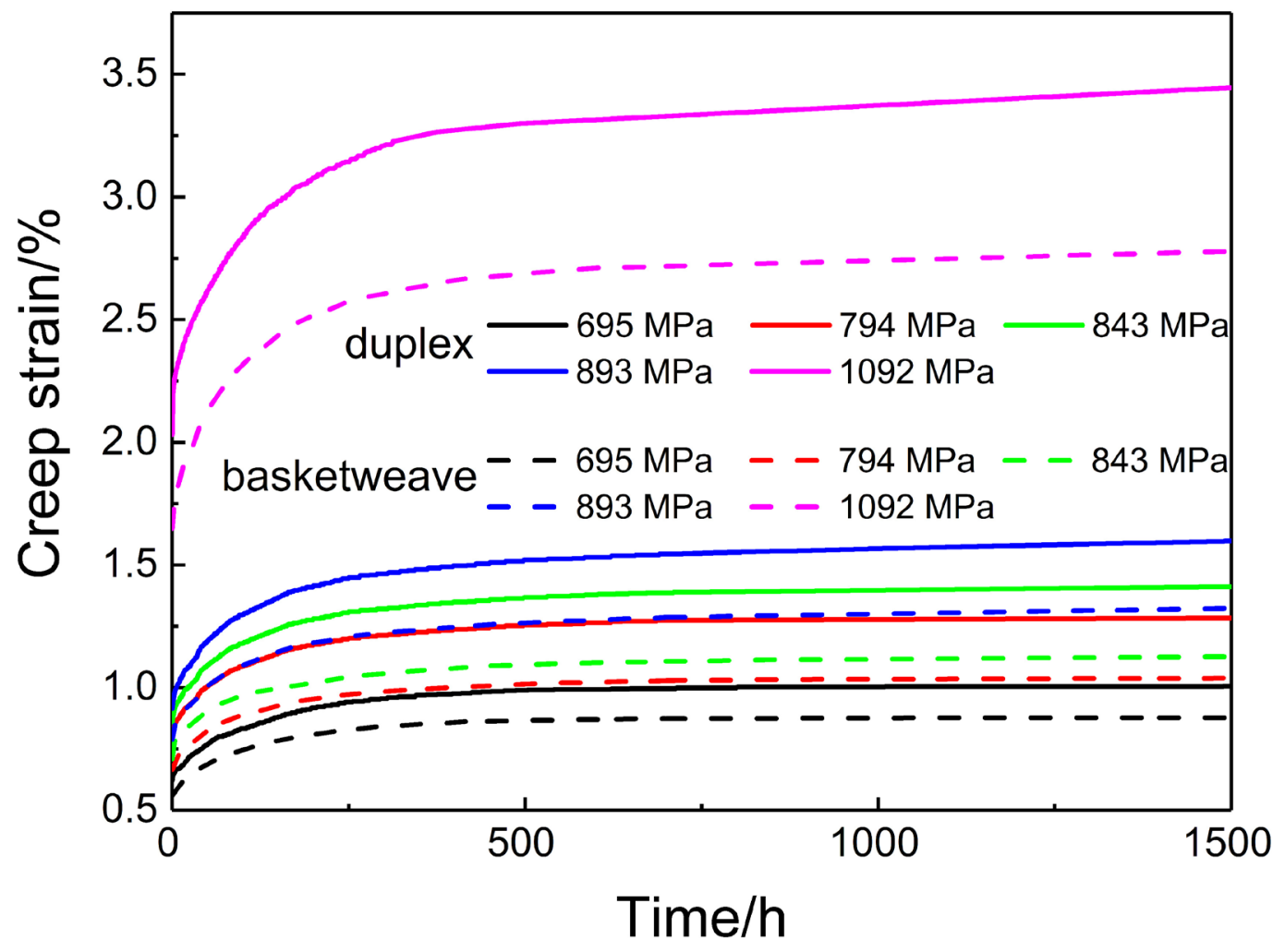

Fig. 4 Compressive creep curves of duplex and basketweave Ti-6Al-4V ELI alloys at different applied compressive stresses.

The creep properties of the Ti-6Al-4V ELI alloys are summarized in Table 1 . The primary creep time decreased with the increase of compressive creep stresses, indicating creep rates reached minimum creep rates more quickly and then maintains constant. The primary creep strains and total creep strains of duplex structure increased slowly at stresses between 695 and $893 \mathrm{MPa}$, which merely increased from $0.38 \%$ to $0.63 \%$ and from $0.38 \%$ and $0.67 \%$, respectively. However, the creep strain increased dramatically at compressive stress of $1092 \mathrm{MPa}$. The primary creep strain and total creep strain reach to $1.24 \%$ and $1.37 \%$. The creep properties of basketweave structure show similar tendency with those of the duplex alloys. The creep deformations of basketweave alloys were less than those of the duplex at all compressive stress levels. These facts prove that the basketweave alloys have better compressive creep resistances. During the HSCCAT of the Ti-6Al-4V ELI alloys, the primary creeps are the dominant deformation forms, consistent with those of other titanium alloys at ambient temperature[19, 20]. The steady-state creep strain rates show similar changing behavior with the primary creep strains and total strains at applied compressive stresses of 700, 740 and $780 \mathrm{MPa}$.

Table 1 Compressive creep data of duplex and basketweave Ti-6Al-4V ELI alloys at different stresses.

\begin{tabular}{cccccc}
\hline $\begin{array}{c}\text { Initial } \\
\text { microstructure }\end{array}$ & $\begin{array}{c}\text { Stress } \\
/ \mathrm{MPa}\end{array}$ & $\begin{array}{c}\text { Primary } \\
\text { creep time } \\
/ \mathrm{h}\end{array}$ & $\begin{array}{c}\text { Primary } \\
\text { creep strain } \\
/ \%\end{array}$ & $\begin{array}{c}\text { Steady-state } \\
\text { creep rate } / \mathrm{s}^{-1}\end{array}$ & $\begin{array}{c}\text { Total creep } \\
\text { strain } / \%\end{array}$ \\
\hline \multirow{5}{*}{ Duplex } & 695 & - & 0.38 & - & 0.38 \\
& 794 & 790 & 0.48 & $3.11 \times 10^{-11}$ & 0.48 \\
& 843 & 750 & 0.53 & $8.05 \times 10^{-11}$ & 0.54 \\
& 893 & 700 & 0.63 & $1.56 \times 10^{-10}$ & 0.67 \\
& 1092 & 410 & 1.24 & $4.07 \times 10^{-10}$ & 1.37 \\
\hline
\end{tabular}




$\begin{array}{cccccc}\text { Basketweave } & 695 & - & 0.32 & - & 0.32 \\ & 794 & 910 & 0.37 & 2.09 \times 10^{-11} & 0.37 \\ & 843 & 870 & 0.40 & 6.30 \times 10^{-11} & 0.41 \\ & 893 & 820 & 0.50 & 1.22 \times 10^{-10} & 0.52 \\ & 1092 & 520 & 1.04 & 2.12 \times 10^{-10} & 1.11\end{array}$

Constitutive equations of creep are usually used to describe the creep behavior and creep lives. The dependent relationship of between the applied stresses and steady-state creep strain rates is frequently expressed in terms of Arrhenius-like equation[7, 9, 10]:

$$
\backslash \operatorname{dot}\{\backslash \text { varepsilon }\}_{-}\{\mathrm{s}\}=\mathrm{A} \backslash \text { sigma } \wedge\{\mathrm{m}\}
$$

Where $\mid \operatorname{dot}\{\mid \text { varepsilon }\}_{-}\{\mathrm{s}\}$ is the steady-state creep strain rate $\left(\mathrm{s}^{-1}\right), A$ is the material constant,

Isigma is the applied stress and $m$ is the stress exponent. A good understanding of stress exponent, $\mathrm{n}$, is necessary to the establishment of creep constitutive equations and the mechanism of steady-state creeps. Fig. 5a shows the HSCCAT data for the duplex Ti-6Al-4V ELI alloys plotted as steady-state strain rates versus stresses on

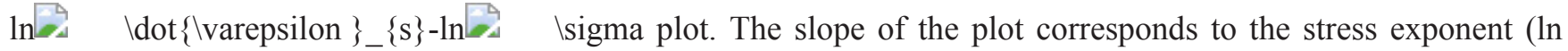
$\backslash \operatorname{dot}\{\mid \text { varepsilon }\}_{-}\{\mathrm{s}\}=\ln A+\mathrm{nln} \quad$ Isigma). The stress exponent calculated from the slope in Fig. 5a is 13.7. The $\mathrm{m}$ value of 13.7 for duplex Ti-6Al-4V ELI alloys was much higher than the reported value for Ti alloys $[\underline{16}, \underline{29}]$ and is consistent with these reports $[4, \underline{30}]$. However, the anomaly $m$ values of the steady-state creep strain rates can be remedied by introducing the threshold stresses $\sigma_{0}$ and effective stresses $\left(\sigma-\sigma_{0}\right)$ into Eq. 1 . The effective stress dependence of the steady-state creep strain rates can be written as following equation $[\underline{4}, \underline{30}]$ :

$\mid \operatorname{dot}\{\mid \text { varepsilon }\}_{-}\{\mathrm{s}\}=\mathrm{A}^{\wedge}\{\hat{}\}\left(\backslash \text { sigma- } \backslash \text { sigma } \_\{0\}\right)^{\wedge}\{\mathrm{m}\}$

Where $A^{\prime}$ is the material constant, $n$ is the effective stress exponent and $\sigma_{0}$ is the threshold stress.

The linear regression of the $n$ value for $2 \wedge \operatorname{dot}\{\mid \text { varepsilon_ }\{\mathrm{s}\}\}^{\wedge}\{1 / \mathrm{n}\}$-Isigma is fitted by iterative method from $n=1$ to $n=12$ and the optimal value of the linear regression is the effective stress exponent. When $n=2.1$, the coefficient of determination $\mathrm{R}^{2}$ is closest to 1 . Therefore, the $\mathrm{n}$ value of the duplex Ti-6Al-4V ELI alloys is

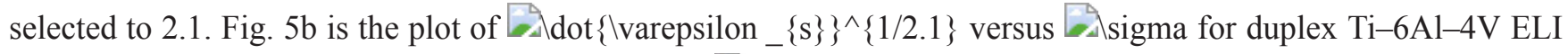
alloys. The extrapolation of the linear regression to ${ }_{\text {A }} \operatorname{dot}\{\mid \text { varepsilon_ }\{\mathrm{s}\}\}^{\wedge}\{1 / 2.1\}=0$ gives the threshold stress. The value of the threshold stress of HSCCAT for duplex Ti-6Al-4V ELI alloys is confirmed to be $710 \mathrm{MPa}$, as illustrated in Fig. 5b. Therefore, the constitutive equation of duplex Ti-6Al-4V ELI alloys in steady state creep can be written as following:

$$
\operatorname{dot}\{\mid \text { varepsilon }\}_{-}\{\mathrm{s}\}=2.77 \backslash \text { times } 10^{\wedge}\{-15\}(\backslash \text { sigma- } 710)^{\wedge}\{2.1\}
$$

The same method is used to process the creep data of the basketweave alloys, as illustrated in Figs. 5c and 5d. The $\mathrm{n}$ value and threshold stress of HSCCAT for the basketweave alloys is confirmed to 1.7 and $740 \mathrm{MPa}$. Therefore, the constitutive equation of basketweave Ti-6Al-4V ELI alloys in steady-state creep can be written as

$$
\backslash \operatorname{dot}\{\mid \text { varepsilon }\}_{-}\{\mathrm{s}\}=2.36 \backslash \text { times } 10^{\wedge}\{-14\}(\text { Isigma- } 740)^{\wedge}\{1.7\}
$$

\subsection{Microstructural changes of Ti-6Al-4V ELI alloys with different microstructure during HSCCAT}

TEM micrographs of duplex Ti-6Al-4V ELI alloy samples before and after HSCCAT at different stress levels are showed in Figs. 6 and 7. The alloys have typical duplex microstructure before HSCCAT, consisting of $\alpha$ and $\beta$ phases, as illustrated in Fig. 6a. There are small amount of dislocations before HSCCATs, which are probably 
formed as a result of plastic deformation during processing. After HSCCAT at $695 \mathrm{MPa}$, dislocations obviously became more than those before the creep, as showed in Fig. 6b. Some wavy dislocations are observed within the equiaxed $\alpha$ phases in Fig. 5b. Many arrays of the straight dislocations are observed in lamellar $\alpha$ phase, which are initially generated at the phase boundaries and then slip in $\alpha$ phases. Similar dislocation substructures have been reported in the previous studies $[18]$. Dislocations in $\alpha$ phases are always hindered by phase boundaries and concentrated at the phase boundaries. The typical dislocation features after HSCCATs at $695 \mathrm{MPa}$ are straight. The operation of a single slip system in $\alpha$ phase regions underwent along (0002) basal planes and cross slip israrely observed. The type of dislocations can be determined by means of diffraction contrast analysis according to invisibility criterion $\quad \operatorname{vec}\{\mathrm{g}\} \backslash \mathrm{cdot} b=0$ as showed in Fig. $6 \mathrm{c}$ and $6 \mathrm{~d}$. The dislocations observed in Fig. $6 \mathrm{c}$ are the a-type or $\mathrm{c}+\mathrm{a}$ type dislocations, while the dislocations observed in Fig. 6d are the c-type or c+a type. Dislocations are distinguished as $\boldsymbol{a}$-type Burgers vector sliding on the (0002) basal planes and a few $\boldsymbol{c}+\boldsymbol{a}$ type sliding on the ( $\quad$ bar $\{2\} 110)$ prism planes.
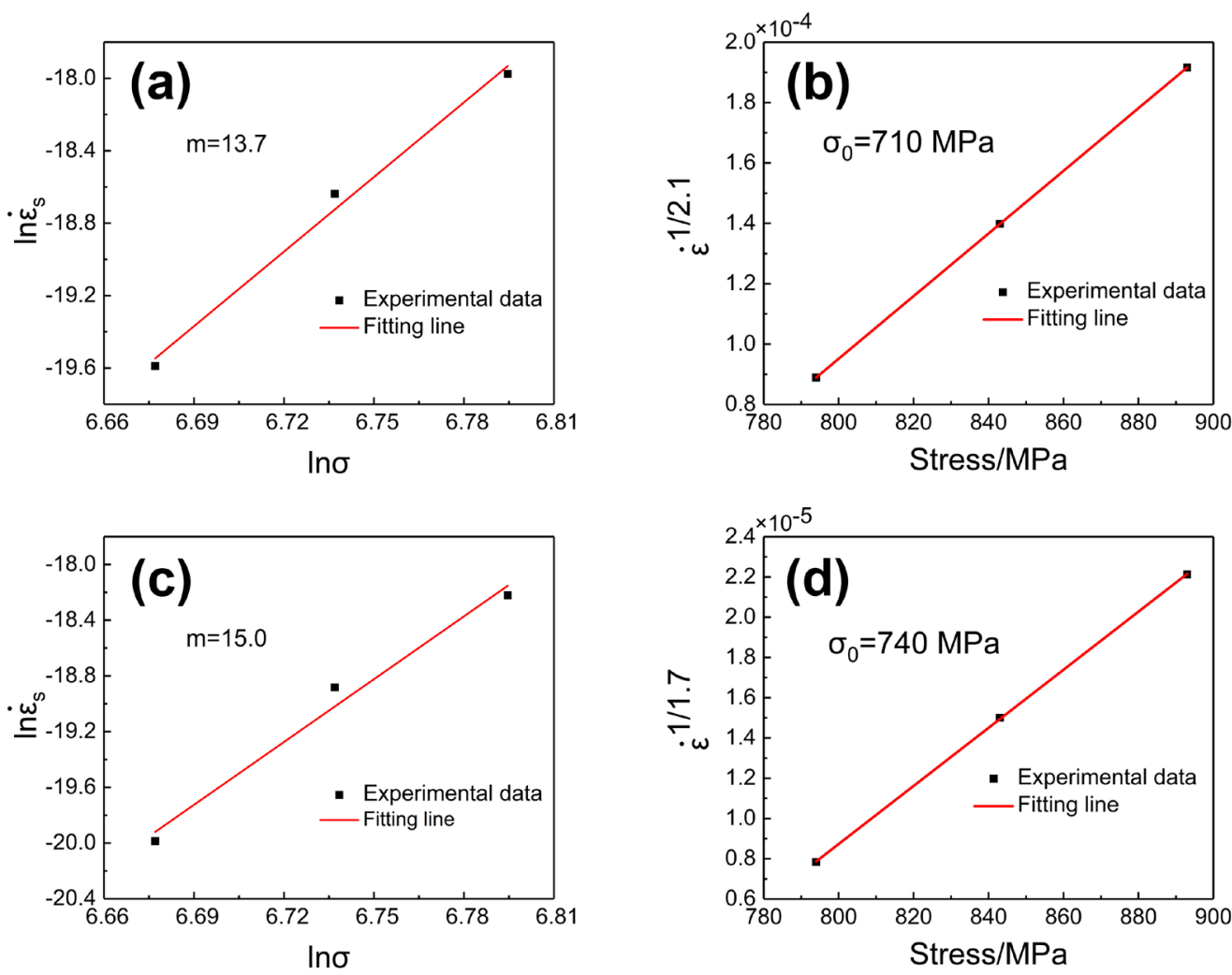

Fig. 5 The stress exponent and threshold stress of Ti-6Al-4V ELI alloys. Double natural logarithmic plots of steady-state creep rate versus stress for duplex (a) and basketweave (b) microstructure; (c) Plots of $\lambda \operatorname{dot}\{\mid \text { varepsilon }\}_{-}\left\{\_\{s\}\right\}^{\wedge}\{\mathbf{1} / \mathbf{2 . 1}\}$ versus stress for duplex microstructure; (d) Plots of $\dot{\varepsilon}_{s}^{1 / 1.7}$ versus stress for basketweave microstructure.

Fig. 7 shows dislocation structure of sample after HSCCAT test at $893 \mathrm{MPa}$. Numerous dislocations are obsevered in $\alpha$ phases and the dislocation density becomes much higher than those before creep or after HSCCAT at low applied stress. In equiaxed $\alpha$ phases, cross slips occurred and a large number of dislocations were tangled as shown in Figs. 7a and 7b, which is believed related to the increase of compressive stresses. The same method has been used to determine the types of dislocations as shown in Figs. 7c and 7d. The dislocations are distinguished as $\boldsymbol{a}$-type Burgers vector sliding on the (0002) basal planes and a few $\boldsymbol{a}$-type sliding on the $(\mathbf{b a r}\{2\} \mathbf{1 1 0})$ prism planes and (Abar $\{2\} 110)$ pyramidal planes. TEM micrographs of basketweave Ti-6Al-4V ELI alloys before and after HSCCAT at different stress levels are showed in Figs. 8 and 9. The results of microscopic dislocation 
movements and reproductions for basketweave alloys are consistent with the duplex. After HSCCAT at $695 \mathrm{MPa}$, dislocations obviously become more than those before and most of dislocations are straight. After HSCCAT test at $893 \mathrm{MPa}$, numerous dislocations are obsevered in $\alpha$ phases and the dislocation density becomes much higher than those before or after HSCCATs at low applied compressive stresses. The dislocations are distinguished as $\mathrm{c}+\mathrm{a}$ type sliding on the pyramidal plane and a-type sliding on the basal or prismatic planes.
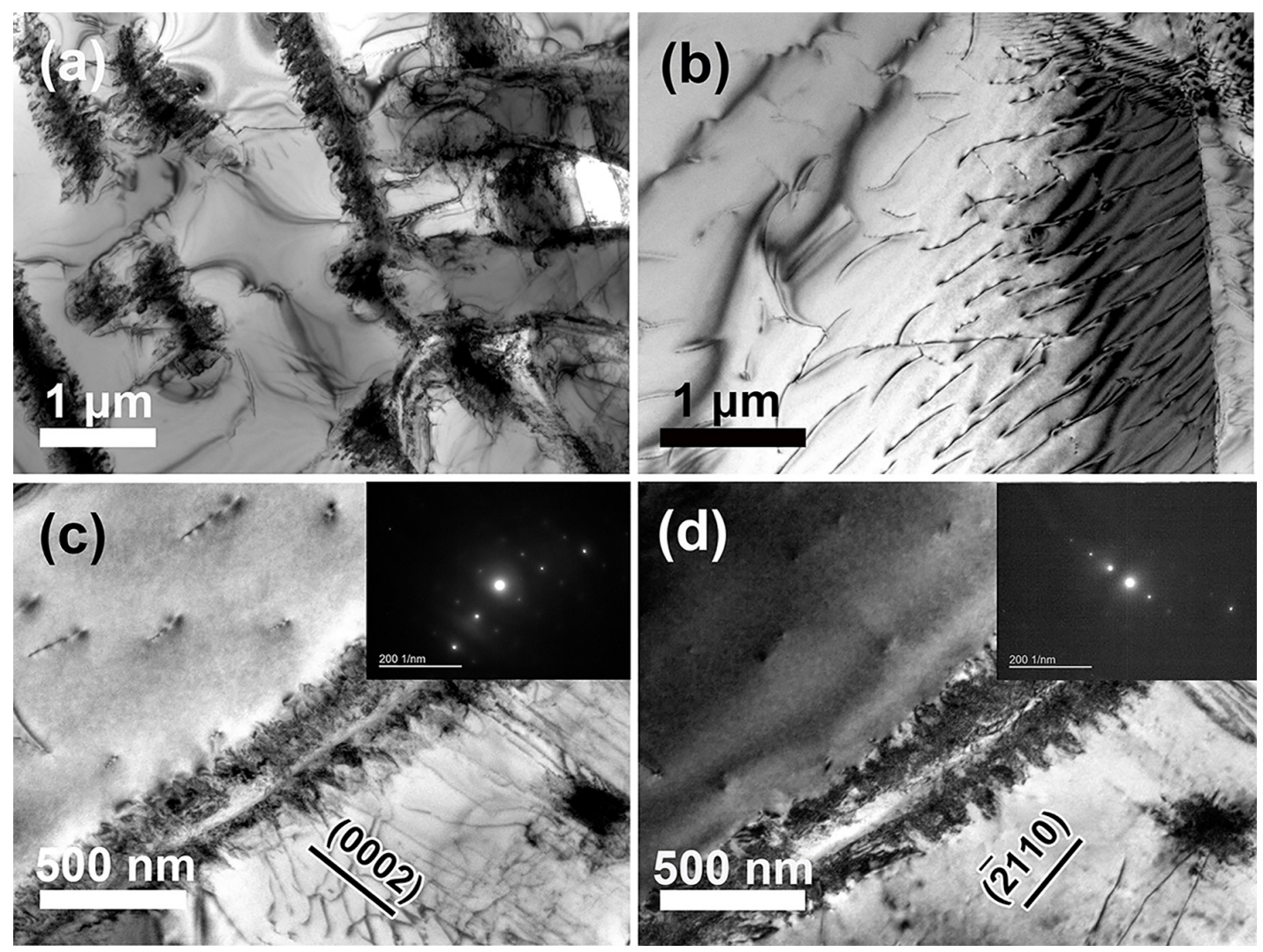

Fig. 6 TEM micrographs of duplex Ti-6Al-4V ELI alloys before (a) and after (b, c, d) HSCCAT at 695 MPa. 

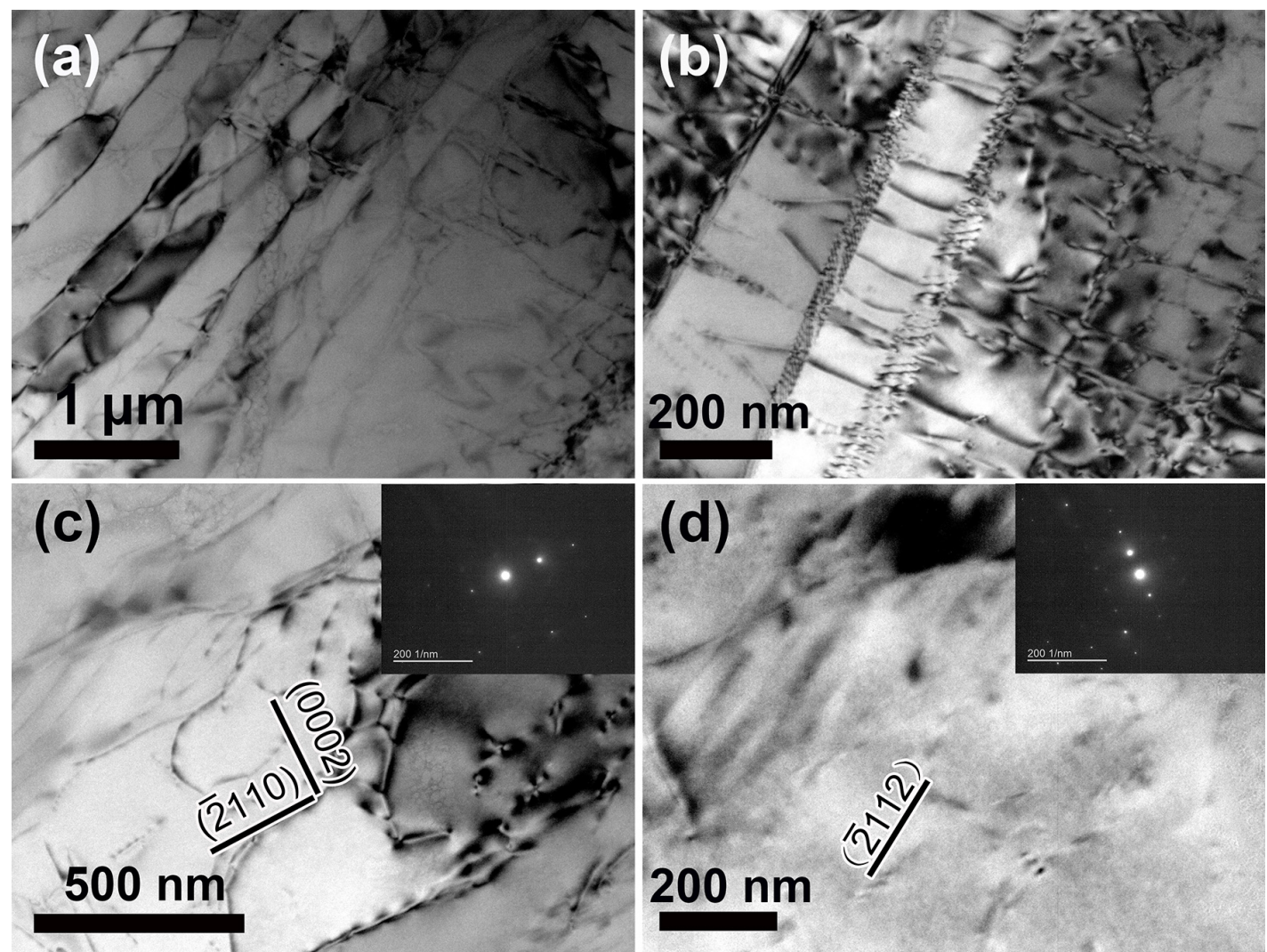

Fig. 7 TEM micrographs of duplex Ti-6Al-4V ELI alloy after HSCCAT at 893 MPa (a, b, c, d).
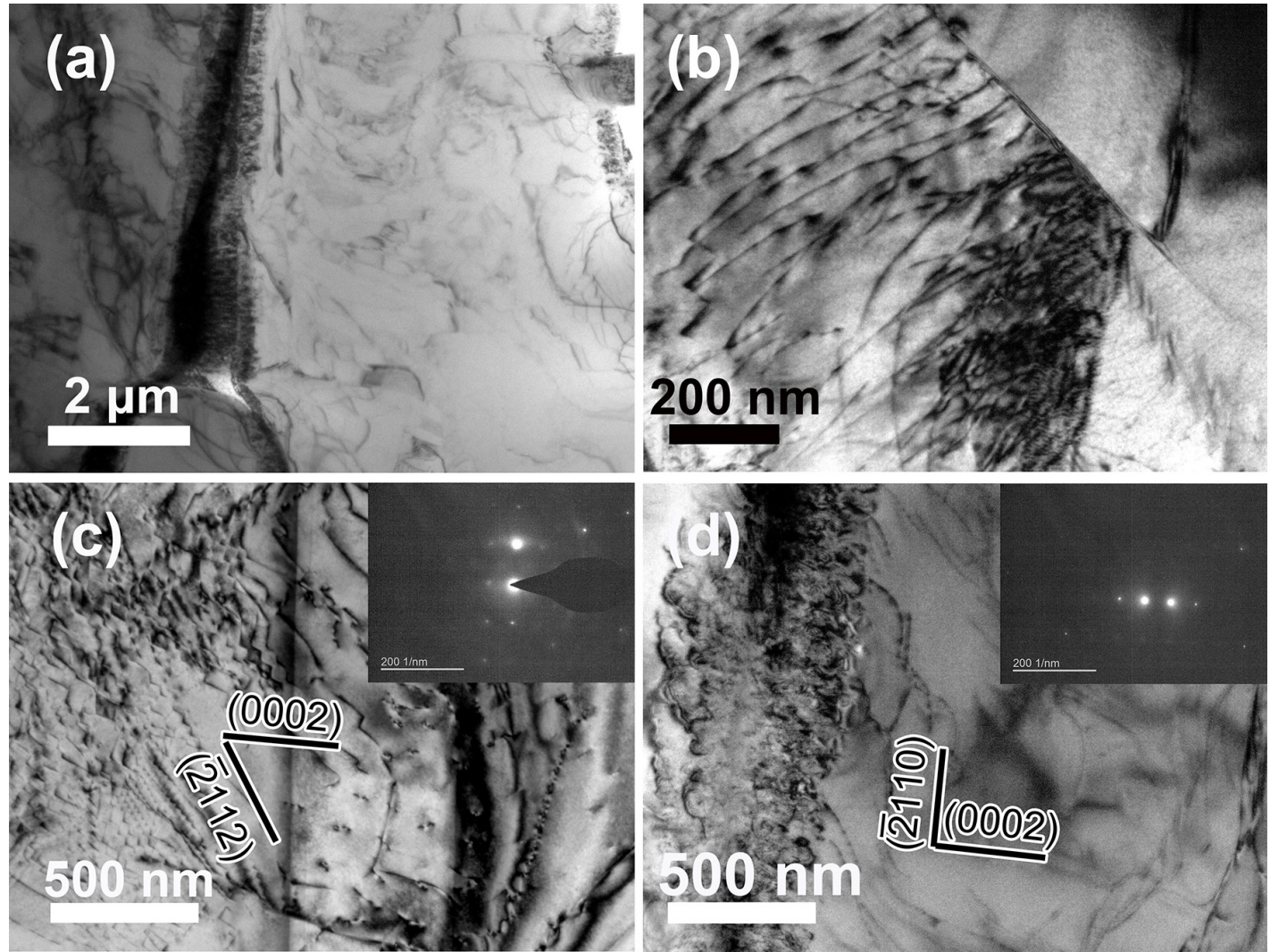

Fig. 8 TEM images of basketweave Ti-6Al-4V ELI alloys before (a) and after (b, c, d) HSCCAT at 695 MPa. 

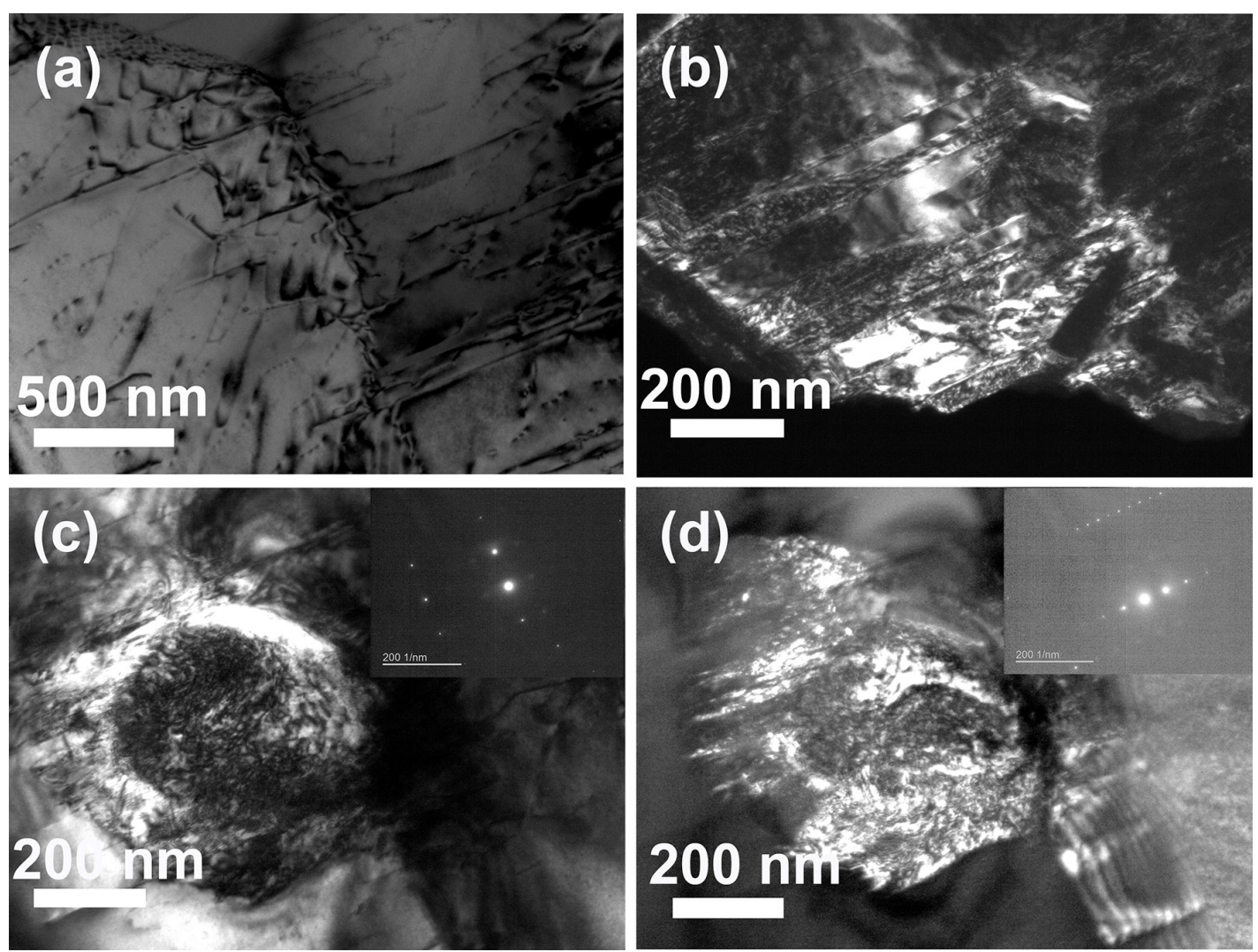

Fig. 9TEM micrographs of basketweave Ti-6Al-4V ELI alloys after HSCCAT at 893 MPa (a, b, c, d).

\section{Discussion}

Typical creep of metals and alloys is generally analyzed in terms of three stages: primary creep, steady-state creeps and accelerated creeps. There is no third creep stage of accelerated creeps, which might to be due to the limited duration time of HSCCAT in the present experimental conditions. There is the presence of the threshold stresses at HSCCATs of Ti-6Al-4V ELI alloys, which is frequently observed in other Ti-based alloys ${ }^{[4]}$ and Mgbased alloys ${ }^{[31]}$. When the stress level is below the threshold stresses, the compressive creeps exhibit creep saturation. However, the creep rates achieve steady-state vaules when the compressive stresses are above the threshold stresses as showed in Fig. 4. At ambient temperature, plastic deformations are mainly due to the movement of dislocations in forms of mobile and immobile dislocations ${ }^{[32]}$. Many mobile dislocations are generated and are able to slip during HSCCATs, resulting in creep deformations. When encountered with parallel dislocations or phase boundaries or other obstacles, mobile dislocations will be trapped in the networks and become immobile dislocations. Immobile dislocation cannot not only slip, but also hinder the slip of the mobile dislocations. The creep strain rates can be calculated by the following equation $[\underline{32}, \underline{33}]$ :

$$
\dot{\varepsilon}=\rho_{m} b v
$$

where $\dot{\varepsilon}$ is the creep strain rate $\left(\mathrm{s}^{-1}\right), \rho_{\mathrm{m}}$ is the mobile dislocation density, $b$ is the Burgers vector and $v$ is the dislocation velocity. Both $\rho_{\mathrm{m}}$ and $v$ are large at the beginning of creep, resulting in maximum $\dot{\varepsilon}$ at the beginning stages of creeps. After moving over free paths, mobile dislocations become immobile. The increase of the immobile dislocations decreases the slip velocity of mobile dislocations, resulting in the gradual decrease of $\dot{\varepsilon}$ 
during the initial periods. When the stress level is below the threshold stresses, dislocations can only slip on a single slip plane. When all the parallel dislocations are plugged together, $\dot{\varepsilon}$ decreases to negligible levels and the compressive creeps exhibit creep saturation. This is consistent with the TEM observation in Fig. 6-9 and all dislocations only slip on a single slip plane and pile up. However, dislocations can slip on multiple slip planes when the stress levels are above the threshold stresses. Therefore, creep deformations can continue to occur, and the creep rates eventually reach steady-state values. In this work, the applied compressive stresses are the main factors that affect the creep deformations during HSCCAT. The larger the applied stresses are, the longer the dislocations can slip, resulting in the larger creep deformations as shown in Fig. 4 and Table 1. In this work, the creep deformations of basketweave Ti-6Al-4V ELI alloys were less than those of the duplex at all stress levels. The threshold stress of basketweave Ti-6Al-4V ELI alloys is higher than that of the duplex during HSCCATs. These facts prove that the basketweave alloys have better creep resistances to the compression deformations than the duplex. This is consistent with other research results $[2, \underline{24}, \underline{25}]$. It is commonly accepted that the lamellar and basketweave alloys have the superior resistances to the tensile creep deformations, followed by bimodal and equiaxed alloys $[\underline{9}, \underline{24}, \underline{25}]$. The lamellar $\alpha$ and $\beta$ phases in the basketweave alloys is semi-coherent relationships meeting Burgers orientation relationship, which have small diffusion rates and dislocation climb rates. However, the primary $\alpha$ phases and the neighboring $\beta$ phases in the duplex microstructures has non-coherent relationships, which have high dislocation climb rates and lead to high creep deformation rates $\underline{23}]$.

The creep mechanism is usually determined by the $\mathrm{n}$ values of effective stress exponent. The different stress exponent $n$ indicates different creep mechanism. According to the classical creep theories, the creeps with $\mathrm{n}$ equal to 1 may correspond to diffusion creep ${ }^{[6]}$. For diffusion creeps, there are two possible kinds caused by diffusion of vacancies through the grains (Nabarro-Herring creep ${ }^{[34]}$ ) or along the grain boundaries (Coble creep ${ }^{[35]}$ ). The stress exponent $\mathrm{n}$ equal to 2 is consistent with grain boundary sliding ${ }^{[38]}$. For the stress exponent $\mathrm{n}$ of 3-8, the creep deformations are controlled by movements of dislocations ${ }^{[38]}$. In the previous reports $[2,4,7,9,11,21,22,26,28,30]$, the researches on the tensile creep deformations of titanium alloys mainly focuses on elevated temperature conditions, however, creep deformations at ambient temperatures under the compressive stresses have not received enough attentions. So the compressive creep deformation mechanism at ambient temperature is not clear yet. The stress exponent $\mathrm{n}$ obtained in this work is 2.1 and 1.7 , corresponding to grain boundary sliding $(n=2)$ mechanism according to the classical creep theories. However, grain boundary sliding mainly occurs at intermediate and elevated temperature and it is difficult to occur at ambient temperature. The stress exponent obtained in this work is similar to the reported value $(n=1.9)$ for Ti-5Al-5Mo-5V-1Fe-1Cr at $400{ }^{\circ} \mathrm{C}[\underline{10]}$, which is controlled by dislocation slip. As shown in TEM micrographs in Figs. 6-9, the main creep deformations are ascribed to the dislocations slips. At ambient temperature, dislocation climb is difficult to happen due to the lack of creep activation energy $[28,30,35]$. Therefore, compressive creep deformation of Ti-6Al-4V ELI alloys during HSCCAT are considered to be mainly controlled by dislocation slip. The creep behavior of Ti-6Al-4V ELI alloys with duplex microstructure is controlled by dislocation slip, and the main movements of the dislocations are a-type Burgers vector sliding on the basal or prismatic planes and a few c+a type sliding on the pyramidal planes. While the mechanism for the basketweave is dislocation slip. The main movements of the dislocations are controlled by $\mathrm{c}+\mathrm{a}$ type Burgers vector sliding on the pyramidal planes and a-type sliding on the basal or prismatic planes. The stress threshold is introduced to reflect the real compressive creep constitutive relationships in the present study. Several works $[\underline{4}, \underline{28}]$ have reported that the creep deformation of materials is driven by effective stress $\left(\sigma-\sigma_{0}\right)$ rather than applied stress. The threshold stresses decrease with increasing temperature and it is relatively small at elevated temperatures (34.47 MPa for Ti-6Al-4V at $873 \mathrm{~K}^{[4]}$ ). Therefore, threshold stresses arenot considered at elevated temperatures. 
However, the threshold stresses of duplex and basketweave Ti-6Al-4V ELI alloys during HSCCATs are 710 and $740 \mathrm{MPa}$ which indicate the difficulty of the appearance of the compressive creep deformations.

\section{Conclusions}

The effects of the initial microstructure and the applied uniaxial compressive stresses ranging from 695 to 1092 $\mathrm{MPa}$ on the compressive creep deformation behavior of Ti-6Al-4V ELI alloys had been investigated by using high-stress compressive creep tests at ambient temperature. The noticeable compressive creep strains occur when the applied compression stresses are higher than the threshold stresses, i.e. $710 \mathrm{MPa}$ for duplex Ti-6Al-4V ELI alloys and $740 \mathrm{MPa}$ for basketweave alloys. The constitutive equations in steady state creep of duplex and basketweave alloys under the interactions of the compressive creep deformations is calculated to be $\backslash \operatorname{dot}\{\mid \text { varepsilon }\}_{-}\{\mathrm{s}\}=2.77 \backslash$ times $10^{\wedge}\{-15\}(\backslash \text { sigma- } 710)^{\wedge}\{2.1\}$ and

$\backslash \operatorname{dot}\{\backslash \text { varepsilon }\}_{-}\{\mathrm{s}\}=2.36 \backslash$ times $10^{\wedge}\{-14\}(\backslash \text { sigma- } 740)^{\wedge}\{1.7\}$. The compressive creep deformation of Ti-6Al-4V ELI alloys is mainly controlled by dislocation slip. The compressive creep deformations of duplex Ti6Al-4V ELI alloys is ascribed to a-type Burgers vector sliding on the basal or prismatic planes and a few c+a type sliding on the pyramidal planes. While the mechanism for the basketweave is dislocation glide with c+a-type Burgers vector sliding on the pyramidal planes and a-type sliding on the basal or prismatic planes.

\section{Acknowledgements}

The authors would also like to acknowledge Jiangsu Collaborative Innovation Center for Advanced Inorganic Function Composites, National Defense Basic Scientific Research Program of China (Grant No. JCKY08414C020), State Key Lab of Advanced Metals and Materials under Grants No. 2018-ZD04, State Key Laboratory of Metal Material for Marine Equipment and Application (Grant No. HG-SKL(2018)06) and Priority Academic Program Development of Jiangsu Higher Education Institution (PAPD).

\section{References}

[1] M. Gerland, P. Lefranc, V. Doquet, C. Sarrazin-Baudoux, Mater. Sci. Eng. A 507 (2009) 132-143.

[2] S. Gollapudi, D.V.V. Satyanarayana, C. Phaniraj, T.K. Nandy, Mater. Sci. Eng. A 556 (2012) 510-518.

[3]H.Hofmann,G. Frommeyer, C.Derder,Mater. Sci. Eng. A 245 (1998) 127-134.

[4] M.J.R. Barboza, E.A.C. Perez, M.M. Medeiros, D.A.P. Reis, M.C.A. Nono, F. P. Neto, C.R.M. Silva, Mater. Sci. Eng. A 428 (2006) 319-326.

[5]J.Koike, K.Maruyama,Mater. Sci. Eng. A 263 (1999) 155-159.

[6] R.W. Hayes, G.B. Viswanathan, M.J. Mills, Acta Mater. 50 (2002) 4953-4963.

[7] M.J.R. Barboza, C.M. Neto, C.R.M. Silva, Mater. Sci. Eng. A 369 (2004) 201-209.

[8] C.J. Boehlert, Mater. Sci. Eng. A 510-511 (2009) 434-439.

[9] Y. Gu, F. Zeng, Y. Qi, X. Xiong, Mater. Sci. Eng. A 575 (2013) 74-85.

[10] X. Nie, H. Liu, X. Zhou, Q. Gao, Mater. Sci. Eng. A 651 (2016) 37-44. 
[11] D.A.P. Reis, C.R.M. Silva, M.C.A. Nono, M.J.R. Barboza, F.P. Neto, E.A.C. Perez, Mater. Sci. Eng. A 399 (2005) 276-280.

[12] L. Ponsonnet, C. Quesne, R. Penelle, Mater. Sci. Eng. A 262 (1999) 50-63.

[13] R.W. Hayes, P.L. Martin, Acta Metall. 43 (1995) 2761-2772.

[14] J.N. Wang, A.J. Schwartz, T.G. Nieh, D. Clemens, Mater. Sci. Eng. A 206 (1996) 63-70.

[15] J. Peng, C.Y. Zhou, Q. Dai, X.H. He, Mater. Sci. Eng. A 611 (2014) 123-135.

[16] H. Tanaka, T. Yamada, E. Sato, I. Jimbo, Scripta Mater. 54 (2006) 121-124.

[17] W. Zhang, Y. Liu, H. Wu, X. Lan, J. Qiu, T. Hu, H. Tang, Mater. Charact. 118 (2016) 29-36.

[18] W.H. Miller, R.T. Chen, E.A. Starke, Metall. Mater. Trans. A 18 (1987) 1451-1468.

[19] T. Yamada, K. Kawabata, E. Sato, K. Kuribayashi, I. Jimbo, Mater. Sci. Eng. A 387 (2004) 719-722.

[20] T. Neeraj, D.H. Hou, G.S. Daehn, M.J. Mills, Acta Mater. 48 (2000) 1225-1238.

[21] F.R.N. Nabarro, Philos. Mag. Lett. 75 (1997) 227-233.

[22] D. Doraiswamy, S. Ankem, Acta Mater. 51 (2003) 1607-1619.

[23] S.L. Semiatin, T.M. Lehner, J.D. Miller,R.D. Doherty, D.U. Furrer, Metall. Mater. Trans. A 38 (2007) 910921.

[24] Z. Abdallah, K. Perkins, S. Williams, Metall. Mater. Trans. A 43 (2012) 4647-4654.

[25] C.M. Omprakash, D.V.V. Satyanarayana, V. Kumar, Mater. Sci. Technol. 26 (2013) 1427-1432.

[26] T. Neeraj, M.F. Savage, J. Tatalovich, L. Kovarik, R.W.Hayes, M.J. Mills, Philos. Mag. 85 (2005) 279-295.

[27] X.Z. Ma, D.Q. Ma, H. Xu, H.Y. Zhang, M.Z. Ma, X.Y. Zhang, R.P. Liu, J. Non-Cryst. Solids 463 (2017) 5663.

[28] J.C.Gibeling, W.D.Nix,Mater. Sci. Eng. 45 (1980) 123-135.

[29] T. Kameyama, T. Matsunaga, E. Sato, K. Kuribayashi, Mater. Sci. Eng. A 510 (2009) 364-367.

[30] W.J. Evans, G.F. Harrison, J. Mater. Sci. 18 (1983) 3449-3455.

[31] T.C. Guo, Y.L. Deng, X.M. Zhang, Y.Y. Zhong, Mater. Sci. Eng. A 527 (2010) 5801-5804.

[32] T.H. Alden, Metall. Mater. Trans. A 18 (1987) 51-62.

[33] S.H. Wang, W. Chen, Mater. Sci. Eng. A 301 (2001) 147-153.

[34] C. Herring, J. Appl. Phys. 21 (1950) 437-445.

[35] R.L. Coble, J. Appl. Phys. 34 (1963) 1679-1682. 